\title{
UPGRADING SEPEDA MOTOR 2 STROKE MENJADI 4 STROKE SEBAGAI UPAYA PENERAPAN STANDARD EMISI EURO 3
}

\author{
UPGRADING MOTORCYCLE 2 STROKE TO 4 STROKE AS \\ APPLICATION OF EURO 3 STANDARD EMISSION
}

\author{
Gusma Hamdana Putra*1), Fiki Ardian Setyo Budi ${ }^{2}$, Esqy Dhiyaul F ${ }^{3)}$, Hangga \\ Krisna $^{4)}$, Agung Slamet Budiono ${ }^{5}$, Aguk Zuhdi Muhammad Fathallah ${ }^{6)}$ \\ 1234)Jurusan Teknik Sistem Perkapalan, ITS \\ 5) Jurusan Teknik Mesin, ITS \\ ${ }^{6)}$ Dosen Pembimbing Teknik Sistem Perkapalan, ITS \\ *Email: putragusmahamdana@yahoo.com
}

\begin{abstract}
Abstrak
Menteri Lingkungan Hidup tahun 2003 tentang “Ambang Batas Emisi Gas Buang Kendaraan Bermotor” yang mengacu Standar Euro 3 telah memberikan dampak yang besar bagi perkembangan kendaraan di Indonesia khususnya motor 2 stroke, dimana pembakaran yang dihasilkan tergolong tidak sempurna dan menghasilkan udara polusi yang berbahaya bagi kesehatan manusia. Sehingga dinilai tidak layak untuk beroperasi lagi di Indonesia. Sehingga motor tersebut tidak berguna dan menimbulkan sampah masal. Melalui penelitian "Upgrading Motor 2 Stroke menjadi Motor 4 Stroke Sebagai Upaya Penerapan Standard Emisi Euro 3" dapat memberikan solusi dari keputusan pemerintah tentang ambang batas emisi gas buang. Selain itu juga untuk meminimalisir sampah masal dari motor 2 stroke yang tidak beroperasi lagi. Dengan memodifikasi motor 2 stroke dan menambahkan komponen dari motor 4 stroke menghasilkan emisi lebih rendah dari motor 2 stroke, serta tidak menghilangkan kelebihan dari performa motor 2 stroke. Sehingga motor ini merupakan solusi yang baik untuk para pecinta motor 2 stroke serta alternatif yang ramah lingkungan.
\end{abstract}

Kata kunci: Emisi Gas Buang, Motor 2 Stroke, upgrading, Motor 4 Stroke

\begin{abstract}
Base on the regulation of the Ministry of Environment at 2003 about "the limitation of the emission of motorcycle" which adopted the Euro 3 standard has been given a huge impact for the development of the motorcycle in Indonesia especially for the 2-stroke motorcycle, where the result of its combustion process can be classified as imperfect combustion process and the Air pollution is harmful for human health. As a result, the 2-stroke engine emission is not feasible to operate in Indonesia. Moreover, in the future, 2-stroke motorcycle will not be used anymore. In our research "Upgrading Motorcycle 2 Stroke To 4 Stroke As Application Of Euro 3 Standard Emission" can give the solution from the regulation of the government about the standard of the gas emission and minimalize the trash from unused motorcycle. With modify 2 -stroke motorcycle and adds some engine components from 4-stroke motorcycle will produce the gas emission lower then 2-stroke motorcycle, but not reduce the 2-stroke engine performance. So that the upgraded motorcycle is the solution for 2-stroke motorcycle users and the alternative way to reduce air pollution.
\end{abstract}

Keywords: Gas Emission, 2-Stroke Motorcycle, Upgrading, 4-Stroke Motorcycle 


\section{PENDAHULUAN}

\section{Latar Belakang}

Kondisi udara kota besar di Indonesia semakin hari semakin mengenaskan. Data Kementrian Lingkungan Hidup menyatakan pencemaran udara akibat motor bensin (spark ignition engine) menyumbang sekitar $70 \% \mathrm{CO}, 100 \% \mathrm{~Pb}, 60 \%$ $\mathrm{HC}$, dan $60 \% \mathrm{NO}_{\mathrm{X}}$. Motor 2 stroke merupakan motor yang dalam satu siklus kerjanya menimbulkan asap yang berlebihan. Akhirnya menimbulkan gas buang beracun yang berbahaya atau istilah populer disebut emisi.

Untuk menanggapi situasi ini, Pemerintah Indonesia mengeluarkan Peraturan Kepmen LH No. 141/2003 tentang emisi gas buang yang diberlakukan pada tanggal 1 Januari 2005 yang mana peraturan itu mengadopsi dari standar emisi eropa Euro 3. Dalam Peraturan tersebut menjelaskan gas buang kendaraan motor 2 stroke dilarang beroperasi. Sehingga akan menimbulkan pertanyaan tentang kelangsungan teknologi mesin 2 Stroke di Indonesia. Motor 2 stroke bisa terancam menjadi tidak berguna dan menimbulkan sampah masal padahal motor 2 stroke ini memiliki keuntungan dalam hal akselerasi. Dengan langkah meng-upgrade motor 2 stroke menjadi 4 stroke, maka akan memberikan solusi ancaman terhadap motor 2 stroke dari standar emisi Euro 3 yang diadopsi oleh Kementrian Lingkungan Hidup.

\section{Perumusan Masalah}

Adapun perumusan masalah dalam penelitian ini adalah sebagai berikut:

a. Bagaimana meng-upgrade sepeda motor 2 stroke menjadi motor 4 stroke?

b. Apakah peforma mesin hasil upgrade setara mesin 4 stroke lainnya?

c. Apakah emisi gas buang mesin hasil upgrade memenuhi regulasi Euro 3?

\section{Tujuan}

Adapun tujuan penelitian ini adalah sebagai berikut : a. Menjelaskan cara upgrade sepeda motor 2 stroke menjadi motor 4 stroke

b. Mengetahui performa mesin hasil upgrade

c. Mengetahui gas buang hasil upgrade untuk memenuhi peraturan Euro 3

\section{Landasan Teori}

\section{Udara Perkotaan Indonesia}

Hasil Evaluasi Kualitas Udara Perkotaan (EKUP) pada tahun 2012 mencapai 44 kota, meningkat dari 26 kota pada tahun 2011. Dan hasil dari uji emisi kendaraan menunjukkan dominasi peningkatan tingkat kelulusan rerata untuk kendaraan bensin dari $85 \%$ di tahun 2011 menjadi 88\% di tahun 2012. (Asdep PPU, Deputi Pengendalian Pencemaran Lingkungan, Kementrian Lingkungan Hidup, 2012). Jumlah kendaraan pada tahun 2011 - 2013 dapat dilihat pada tabel 1.

Tabel 1. Jumlah Kendaraan Tahun 2011 - 2013

\begin{tabular}{llrrr}
\hline \multirow{2}{*}{ No } & \multirow{2}{*}{ Jenis Kendaraan } & \multicolumn{3}{c}{ Tahun } \\
\cline { 3 - 5 } & & \multicolumn{1}{c}{2011} & \multicolumn{1}{c}{2012} & \multicolumn{1}{c}{2013} \\
\hline 1 & Mobil penumpang & 8.540 & 9.525 & 10.540 \\
2 & Bus & 1.920 & 1.945 & 1.965 \\
3 & Sepeda motor & 69.205 & 77.756 & 86.253 \\
4 & Kendaraan & 4.257 & 4.723 & 5.165 \\
& lainnya & & & \\
5 & Jumlah total & 83.922 & 93.949 & 103.923 \\
\hline
\end{tabular}

Sumber : Korlantas Polri (2013)

\section{Motor 2 Stroke}

Asif Faiz, Christopher S. Weaver \& Michael P. Walsh (1996) menjelaskan bahwa motor 2 stroke memiliki satu siklus kerja yaitu dua kali naik turun piston. Sehingga tergolong motor yang ringan dan menghasilkan power output yang besar. Tidak menggunakan katup untuk sistem pembilasannya, namun sistem pembilasannya dicampur dengan sistem pelumasan yang ada di ruang bakar. Hal ini yang mengakibatkan gas buang motor 2 stroke memiliki nilai emisi yang sangat tinggi. 


\section{Standar Emisi Gas Buang}

Standar emisi adalah salah satu faktor utama yang menjadi penilaian kualitas udara di Indonesia. Untuk standar emisi maksimal di negara Eropa sangat kecil. Standar emisi gas buang dapat dilihat ada Tabel 2 .

Tabel 2. Standar Emisi Gas Buang Eropa

\begin{tabular}{lrrr}
\hline Engine & \multicolumn{1}{c}{ HC } & \multicolumn{1}{c}{ CO } & \multicolumn{1}{c}{ NOx } \\
\hline 2 Stroke & 1,00 & $0,80-1,00$ & $0,10-0,25$ \\
4 Stroke & 0,15 & 1,00 & 1,00 \\
\hline
\end{tabular}

Sumber : Manufactures of Emission Control Association (1999, p. 8)

\section{Peraturan Pemerintah Emisi Gas Buang}

Melihat kondisi kualitas udara di Indonesia, pemerintah mengeluarkan Peraturan Menteri Lingkungan Hidup No. 04 tahun 2009 tentang Ambang Batas Emisi Gas Buang Kendaraan Bermotor Tipe Baru dengan Kategori L3.

\section{Nilai Ambang Batas}

Nilai ambang batas adalah kadar maksimum yang diperbolehkan.

Nilai ambang batas untuk kategori kendaraan dapat dilihat pada Tabel 3.

Tabel 3. Nilai Kategori Ambang Batas

\begin{tabular}{lllcc}
\hline No & \multicolumn{1}{c}{ Kategori } & \multicolumn{1}{c}{ Parameter } & Nilai Ambang Batas (gr/km) & Metode Uji \\
\hline 1 & L1 & CO & 1,00 & ECE R 47 \\
2 & L2 & HC+NOx & 1,20 & ECE R 47 \\
& & HC+NOx & 3,50 & \\
3 & L3 $<150 \mathrm{~cm}^{3}$ & CO, HC, NOx & 5,$50 ; 1,20 ; 0,30$ & ECE R 47 \\
4 & L3 $2150 \mathrm{~cm}^{3}$ & CO, HC, NOx & 5,$50 ; 1,00 ; 0,30$ & ECE R 47 \\
5 & L4 \& L5 motor bakar cetus api & CO, HC, NOx & 7,$00 ; 1,50 ; 0,40$ & ECE R 47 \\
6 & L4 \& L5 motor bakar penyalaan & CO, HC, NOx & 2,$00 ; 1,00 ; 0,65$ & ECE R 47 \\
& kompress & & \\
\hline
\end{tabular}

Catatan :

1. L1 : Kendaraan beroda 2, kapasitas silinder mesin tidak lebih dari $50 \mathrm{~cm}^{3}$

2. L2 : Kendaraan beroda 3, susunan roda sembarang, kapasitas silinder mesin tidak lebih dari $50 \mathrm{~cm}^{3}$

3. L3 : Kendaraan beroda 2, kapasitas silinder lebih dari $50 \mathrm{~cm}^{3}$

4. L4 : Kendaraan beroda 3, susunan roda asimetris, kapasitas silinder mesin lebih dari $50 \mathrm{~cm}^{3}$

5. L5 : Kendaraan beroda 3, susunan roda simetris, kapasitas silinder mesin lebih dari 50 $\mathrm{cm}^{3}$

\section{Sistem Pelumasan}

Sistem pelumasan pada motor 2 stroke menggunakan 2 pelumasan, sistem pelumasan untuk pembakaran dan sistem pelumasana untuk gesekan antar gear. Dan untuk sistem pelumasaan 4 stroke hanya menggunakan satu sistem pelumasan pada gesekan antar gear. Pada sistem pelumasan motor 2 stroke khususnya pada sistem pembakaran inilah yang menghasilkan emisi yang besar. Dikarenakan pembakarannya yang tidak merata, tekanan minim, serta melibatkan oli untuk ikut dibakar bersama fuel dan udara. Oleh karena itu perlunya perubahan sistem pelumasan untuk mereduksi hasil gas pembuangan. Yaitu dengan merubah sistem pelumasan sesuai dengan sistem pelumasan motor 4 stroke dengan memodifikasi komponen tabung (casing) pembakaran sesuai dengan motor 4 stroke. 


\section{METODA}

Metode Pelakasanaan dari PKM-Penelitian ini menggunakan Metode Reverse Engineering, dimana akan dijelaskan pada diagram alur dibawah ini :

a. Penentuan Sepeda Motor

Sepeda motor ini adalah sepeda motor 2 stroke yang paling umum dimiliki oleh banyak orang dan mudah didapatkan spare partnya.

b. Penentuan Silinder yang akan dipasang

Pada proses ini menggunakan silinder pembakaran 4-Stroke dari mesin jupiter $\mathrm{Z}$ dengan alasan adanya kesamaan merk dari mesin dan komponen mesin jupiter $\mathrm{Z}$ banyak di pasaran.

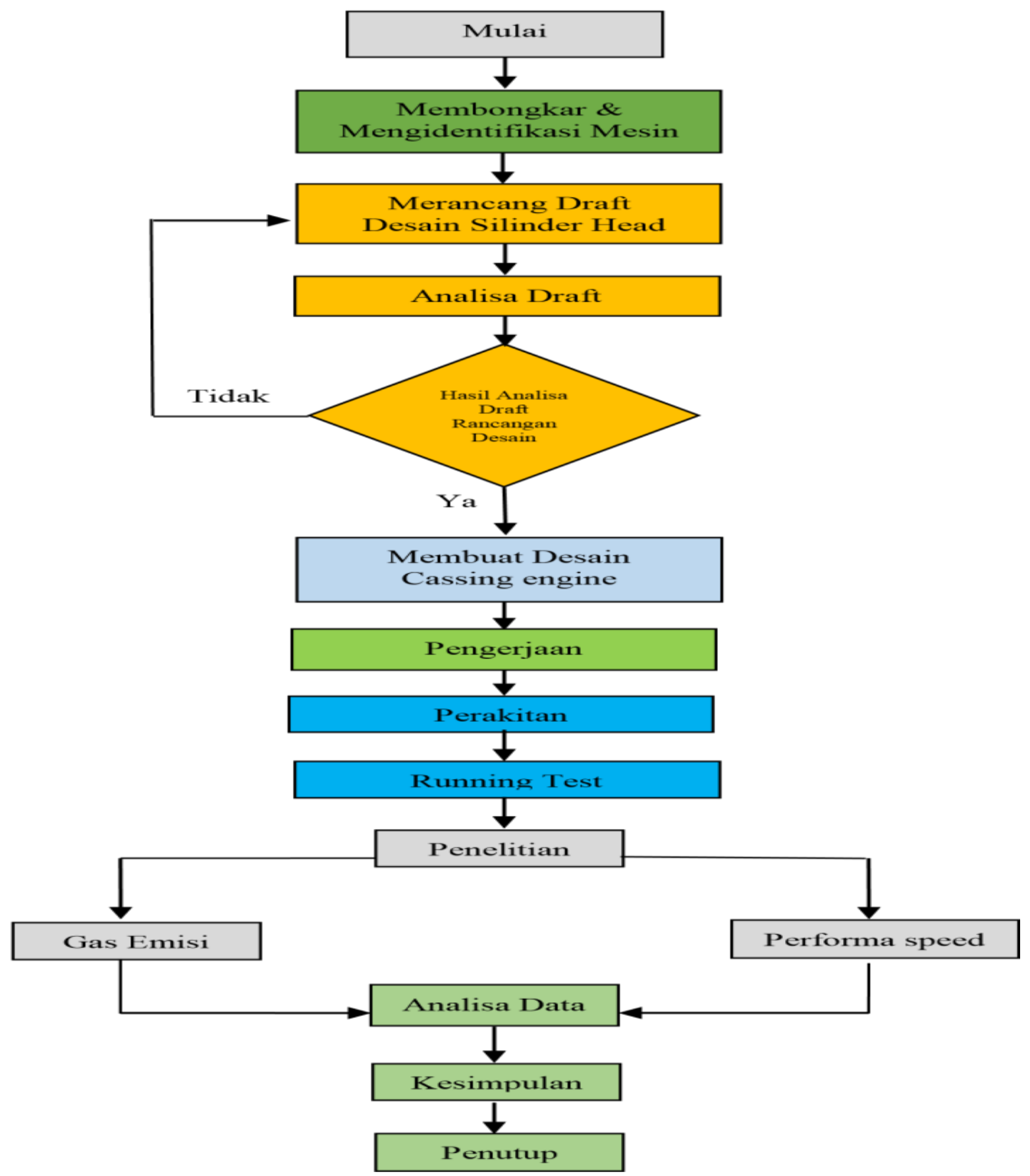

Gambar 1. Metode Penelitian 


\section{Pembongkaran Mesin}

Pembongkaran mesin dilakukan pada seluruh komponen yaitu mulai dari silinder pembakaran dan engine casing. Komponen yang sudah dibongkar, lalu dipelajari, kemudian di modifikasi dan diganti.

\section{Komponen yang akan diganti}

a. Silinder pembakaran beserta isi

Silinder pembakaran diganti menggunakan mesin 4-Stroke.

b. Crank Shaft dan conecting road

Crank Shaft dan conecting road diganti untuk mempermudah penyesuaian Titik Mati Atas (TMA) dan Titik Mati Bawah (TMB) dalam pembakaran.

c. Sistem Kelistrikan

Sistem kelistrikan mesin 2 stroke berbeda dengan 4 stroke karena dengan perbedaan durasi percikan busi yang bersumber dari CDI.

d. Suplai bahan bakar

Karburator yang di pakai adalah karburator Jupiter $\mathrm{Z}$ dengan alasan penyesuaian proses pembakaran.

\section{e. Muffler}

Knalpot/ muffler yang dipakai adalah jupiter z dengan tujuan meredam kebisingan dan menyaring gas emisi yang keluar dari pembakaran.

Gambar 2 yaitu motor Fiz R, motor yang akan dilakukan pembongkaran mesin. Sedangkan pada Gambar 3 dan Gambar 4 dapat dilihat gambar pada saat pembongkaran mesin dan gambar setelah mesin Fiz $\mathrm{R}$ telah dibongkar. Didalam mesin inilah terdapat beberapa komponen yang nantinya akan diganti.

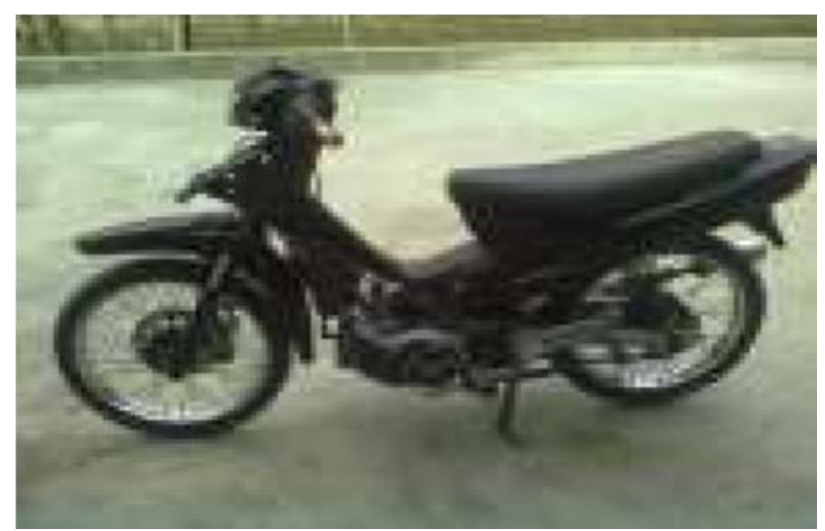

Gambar 2. Motor Fiz-R

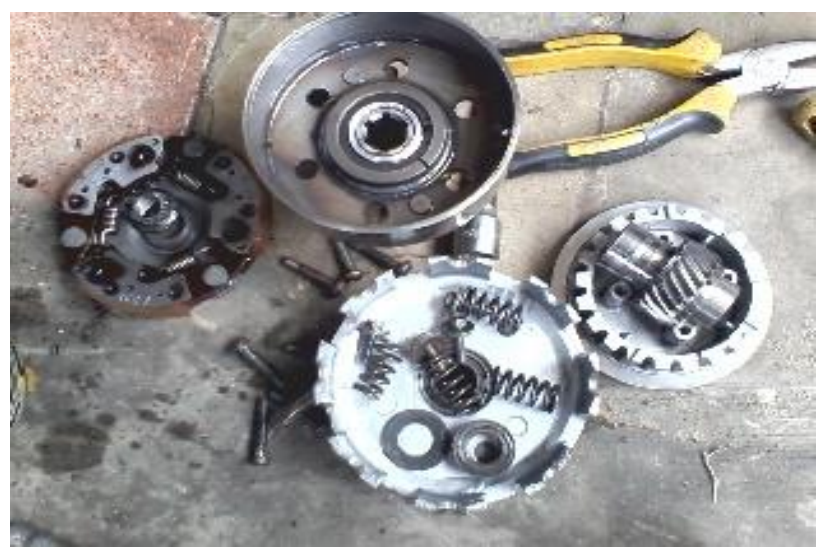

Gambar 3. Pembongkaran Mesin

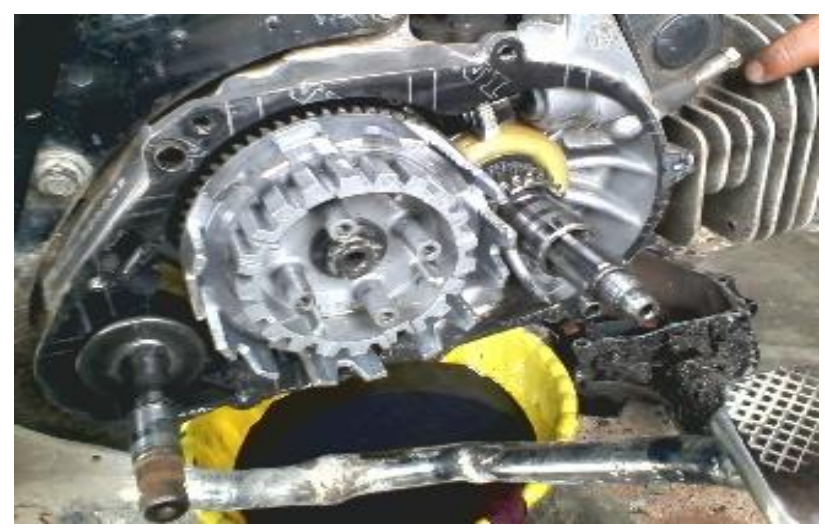

Gambar 4. Mesin Fiz-R

\section{Perancang draft desain}

\section{Komponen yang di pertahankan}

Hampir semua komponen motor 2 stroke itu dipertahankan kecuali silinder pembakaran beserta isinya dan pendukung pembakaran di ganti dengan 4 stroke. Pada gear/gigi pada mesin Fiz-R sudah tidak dapat dipertahankan 

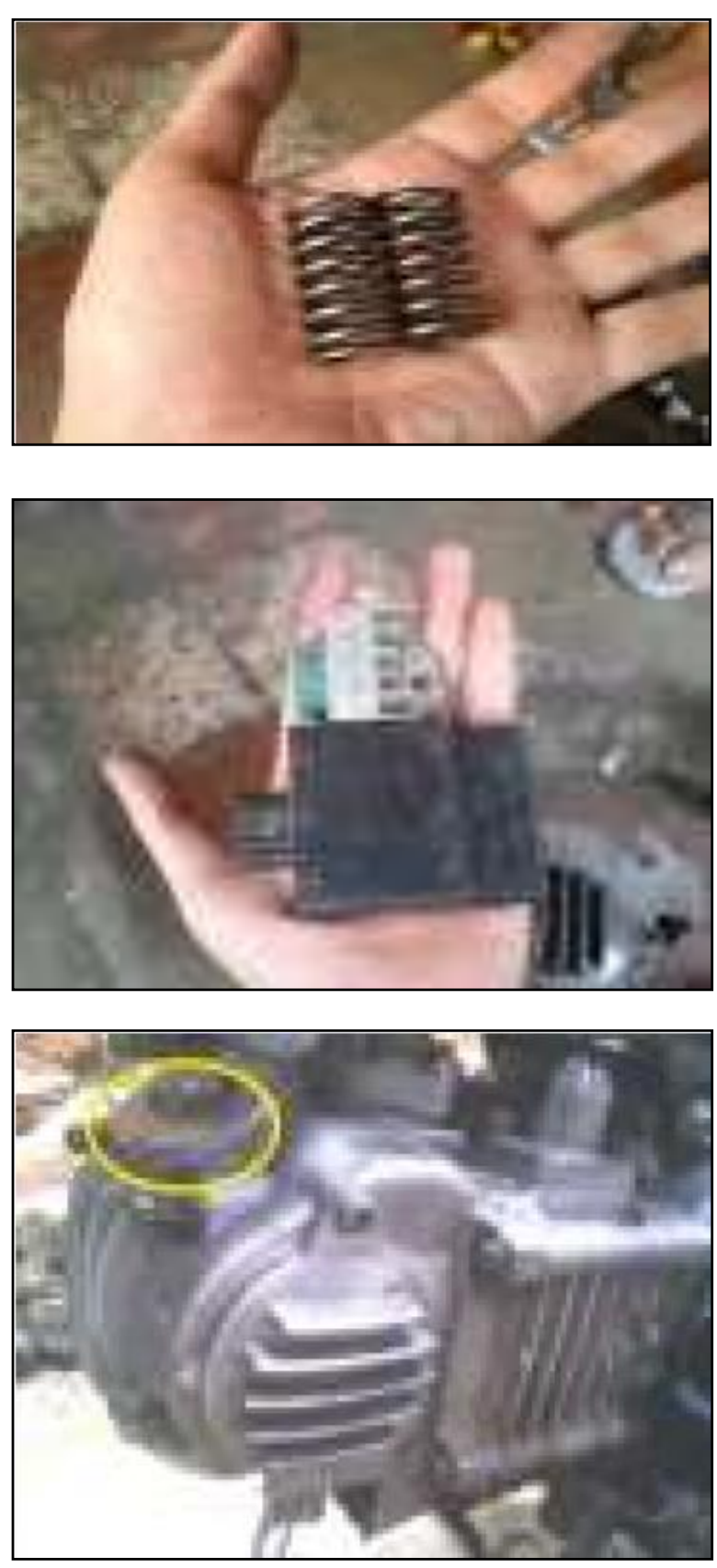

Gambar 5. Komponen Mesin Fiz-R

Komponen yang dimodifikasi

\section{a. Cassing engine}

Cassing engine dimodifikasi, penyesuaian dengan silinder 4 stroke.

\section{b. Timming Gear}

Timming gear ini dipasangkan untuk mengatur durasi buka tutup katub yang ada disilinder head.

c. Lubang Karbulator 2 stroke
Lubang karbulator 2 stroke dimodifikasi dengan ditutup menggunkan las.

\section{Analisa Draft}

a. Desain Cassing Engine

Berikut desain modifikasi cassing engine yang akan digambarkan dibawah ini:
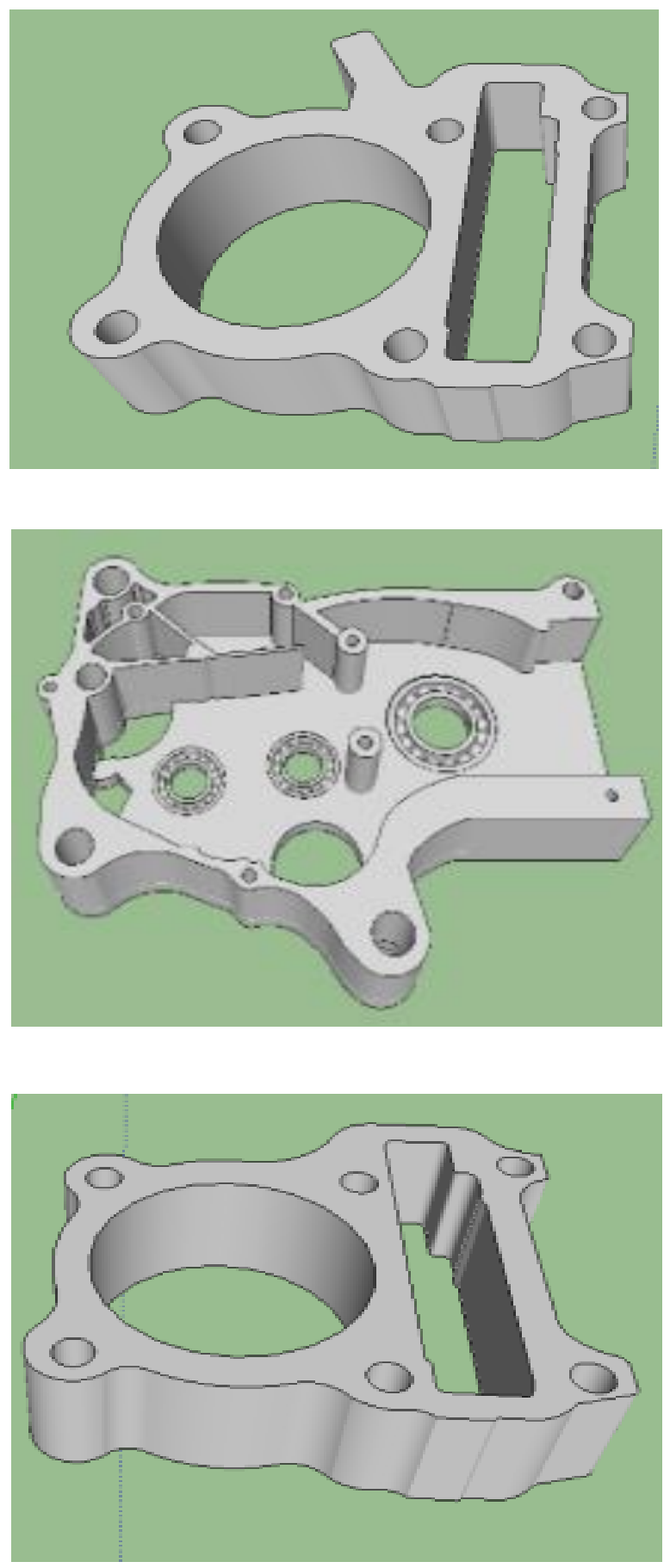

Gambar 6. Desain Engine Cassing 


\section{Pengerjaan Logam}

a. Pengelasan Diral

Pengelasan diral dilakukan bertujuan menambah kontruksi di casing engine.

b. Proses Pembubutan

Membubut lubang crank shaft supaya didapatkan hasil yang halus pada permukaan yang melingkar.

\section{c. Proses Frais}

Proses ini dilakukan dengan tujuan finising dan penghalusan permukaan casing engine.

\section{Perakitan}

Perakitan dilakukan dengan tujuan menjadi komponen Motor 4 stroke hasil upgrade.

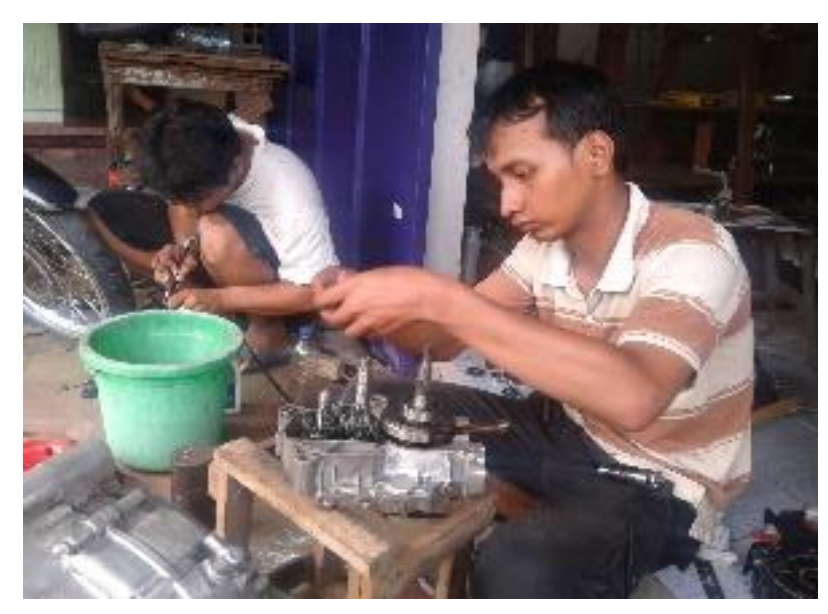

Gambar 7. Perakitan Komponen

\section{Running Test}

Sebelum diuji, Motor dirunning test pada jarak pendek sekitar kampus dan Surabaya.

\section{Uji Motor Upgrade}

\section{a. Uji Gas Emisi}

Uji ini menggunakan metode idle dengan satuan $\%$ volume yang selanjutnya dikonversi menjadi satuan $\mathrm{g} / \mathrm{Km}$.

b. Uji Engine Performa Speed
Uji dilakukan konstan load dengan variasi kecepatan dan posisi gigi dan beban $50 \mathrm{~kg}$.

\section{Analisa Data}

Analisa data didapatkan dari pengujian model pada tiap - tiap variable serta menampilkan data tersebut dalam grafik. Untuk jelasnya akan dibahas di bab 4.

\section{HASIL DAN PEMBAHASAN}

\section{Uji Gas Emisi}

\section{a. Hasil Gas Emisi}

Pengujian gas emisi menggunakan metode idle. Pengujian ini menggunakan variasi putaran mesin menjadi 3 bagian yaitu:

1. Kondisi stationer, mesin berjalan kurang lebih 1000 RPM

2. Kondisi medium merupakan kondisi sepeda motor dengan menarik trotle setengah dati total putaran trotle, Mesin berputar pada 5000-6000 RPM

3. Top speed merupakan kondisi sepeda motor dengan menarik trotle sampai batar atas, mesim berputas pada 9000-10000 RPM

Dalam pengujian gas emisi didapatkan data di bawah ini.

Tabel 4. Hasil Uji Gas Emisi

\begin{tabular}{lrrr}
\hline $\begin{array}{c}\text { Putaran } \\
\text { Kandungan }\end{array}$ & $\begin{array}{r}\text { Stationary } \\
\text { Condition }\end{array}$ & $\begin{array}{c}\text { Medium } \\
\text { Speed }\end{array}$ & \multicolumn{1}{c}{$\begin{array}{c}\text { Top } \\
\text { Speed }\end{array}$} \\
\hline $\mathrm{CO}(\%$ Vol $)$ & 1,501 & 0,759 & 1,437 \\
$\mathrm{CO}_{2}(\%$ Vol $)$ & 0,950 & 1,346 & 2,456 \\
$\mathrm{HC}(\mathrm{PPM}$ Vol $)$ & 514,048 & 59,630 & 2799,130 \\
$\mathrm{O}_{2}(\%$ Vol $)$ & 17,901 & 18,47 & 15,703 \\
\hline
\end{tabular}

Tabel 5. Parameter Kategori L

\begin{tabular}{ccccc}
\hline Kategori & $\begin{array}{c}\text { Tahun } \\
\text { Pembuatan }\end{array}$ & \multicolumn{2}{c}{ Parameter } & Metode \\
(\%) & HC & (ppm) & Uji \\
$\begin{array}{c}\text { Sepeda Motor } \\
\text { 2 stroke }\end{array}$ & $<2010$ & 4,5 & 12.000 & Idle \\
$\begin{array}{c}\text { Sepeda Motor } \\
\text { 4-Stroke }\end{array}$ & $<2010$ & 5,5 & 2.400 & Idle \\
$\begin{array}{c}\text { Sepeda Motor } \\
\text { 2 \& 4-Stroke }\end{array}$ & $\geq 2010$ & 4,5 & 2.000 & Idle \\
\hline
\end{tabular}


Tabel 6. Hasil Konversi dari Idle ke ECE R 40 pada Medium Speed

\begin{tabular}{cccc}
\hline Sepeda Motor & $\begin{array}{c}\mathbf{C O} \\
(\mathbf{g r} / \mathbf{K m})\end{array}$ & $\begin{array}{c}\mathbf{C O}_{2} \\
(\mathbf{g r} / \mathbf{K m})\end{array}$ & $\begin{array}{c}\mathbf{H C} \\
(\mathbf{g r} / \mathbf{K m})\end{array}$ \\
\hline Sepeda Upgrading & 4.086295 & 7.2585498 & 0.03206 \\
\hline
\end{tabular}

Tabel 7. Ambang Batas Emisi EURO 3

\begin{tabular}{|c|c|c|c|c|}
\hline \multirow{2}{*}{ Class } & Mass of CO & Mass of $\mathrm{HC}$ & $\begin{array}{c}\text { Mass of Oxides of } \\
\text { Nitrogen }\end{array}$ & Mass of CO \\
\hline & $\begin{array}{c}\mathbf{L 1} \\
(\mathrm{g} / \mathrm{km})\end{array}$ & $\begin{array}{c}\mathbf{L 2} \\
(\mathrm{g} / \mathrm{km})\end{array}$ & $\begin{array}{c}\mathbf{L 3} \\
(\mathrm{g} / \mathrm{km})\end{array}$ & $\begin{array}{c}\mathbf{L 1} \\
(\mathrm{g} / \mathrm{km})\end{array}$ \\
\hline \multicolumn{5}{|c|}{ Limit value for motorcycle (two wheel) for type approval and conformity of production } \\
\hline \multirow{2}{*}{ A (2003) } & $\mathrm{I}\left(<150 \mathrm{~cm}^{3}\right)$ & 5,5 & 1,2 & 0,3 \\
\hline & II $\left(\geq 150 \mathrm{~cm}^{3}\right)$ & 5,5 & 1,0 & 0,3 \\
\hline \multirow{4}{*}{ B (2006) } & $\mathrm{I}\left(<150 \mathrm{~cm}^{3}\right)$ & & & \\
\hline & (UDC cold) & 2,0 & 0,8 & 0,15 \\
\hline & II $\left(\geq 150 \mathrm{~cm}^{3}\right)$ & & & \\
\hline & (UDC + EUD cold) & 2,0 & 0,3 & 0,15 \\
\hline \multicolumn{5}{|c|}{ Limit value for motorcycle (two wheel) for type approval and conformity of production (positive ignition) } \\
\hline A (2003) & ALL & 7,0 & 1,5 & 0,4 \\
\hline \multicolumn{5}{|c|}{ Limit value for motorcycle (two wheel) for type approval and conformity of production (compression ignition) } \\
\hline A (2003) & ALL & 2,0 & 1,0 & 0,65 \\
\hline
\end{tabular}

Tabel 8. Perbandingan Gas Emisi

\begin{tabular}{crrrr}
\hline Sepeda Motor & CO $(\%$ vol $)$ & CO $_{2}(\%$ vol $)$ & HC $(\mathbf{p p m})$ & O $_{2}(\%$ vol $)$ \\
\hline${\text { Yamaha Vega }\left(4-\text { stroke }^{*}\right.}^{*}$ & 1.984 & 6.1 & 137.4 & 9.748 \\
Yamaha RX King (2-Stroke) $)^{* *}$ & 2.34 & 14.23 & 56.757 & 1.845 \\
Sepeda Upgrading & 0.759 & 1.346 & 59.63 & 18.147 \\
\hline
\end{tabular}

\footnotetext{
* Sihatupar, Riman (2011)

** Siswantoro, dkk., (2012)
}

\section{Perbandingan Gas Emisi}

Tabel 7 menjelaskan hasil konversi dari kondisi idle ke ECE R 40 pada keadaan medium speed. Yang selanjutnya dibandingkan dengan Tabel 8 tentang ambang batas emisi Euro 3. Dan terakhir pada Tabel 8 menjelaskan perbandingan antara motor hasil upgrading dengan motor 2 stroke maupun 4 stroke.

\section{Penelitian Engine Performa Speed}

Pengujian menggunakan dyno test ini bertujuan untuk mengetahui karakteristik power dan torsi pada beban konstan yaitu $50 \mathrm{Kg}$. Seperti yang dapat dilihat pada Tabel 9. Sedangkan kebutuhan bahan bakar dapat dilihat pada Tabel 10 dan Gambar 8. 
Tabel 9. Engine Performance

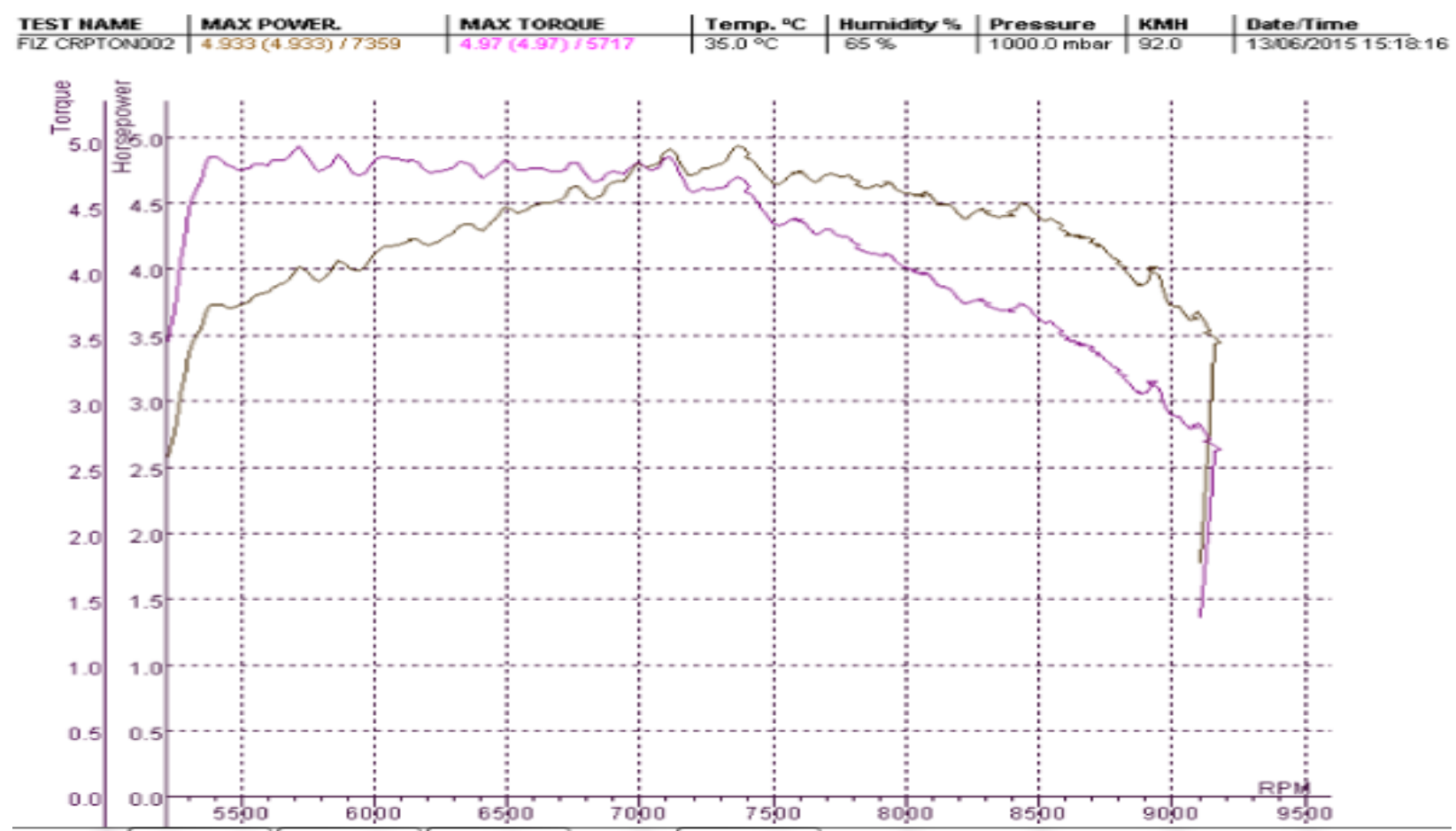

Tabel 10. Analisa Kebutuhan Bahan Bakar

\begin{tabular}{|c|c|c|c|c|c|c|c|}
\hline No. & RPM & Posisi Gigi & Power (Hp) & Torsi & $\begin{array}{c}\text { Volume Bahan } \\
\text { Bakar }(\mathrm{ml})\end{array}$ & Waktu (s) & SFC \\
\hline \multirow[t]{4}{*}{1.} & & 1 & 5,216 & 4,39 & 3 & 7,77 & 0,2398323 \\
\hline & & 2 & 6,231 & 5,18 & 2 & 7,24 & 0,14364109 \\
\hline & 8500 & 3 & 4,978 & 4,13 & 2 & 5,24 & 0,2484213 \\
\hline & & 4 & 4,213 & 3,5 & 2 & 4,31 & 0,35686691 \\
\hline \multirow[t]{4}{*}{2.} & & 1 & 4,254 & 4,66 & 3 & 10,55 & 0,21657899 \\
\hline & & 2 & 5,848 & 6,01 & 2 & 6,12 & 0,18105738 \\
\hline & 7000 & 3 & 5,337 & 5,38 & 2 & 5,48 & 0,221563 \\
\hline & & 4 & 4,802 & 4,84 & 2 & 5,38 & 0,25082486 \\
\hline \multirow{4}{*}{3.} & & 1 & 3,439 & 4,51 & 3 & 14,97 & 0,18880448 \\
\hline & 5500 & 2 & 4,405 & 5,69 & 2 & 9,04 & 0,16272739 \\
\hline & & 3 & 4,309 & 5,53 & 2 & 8,49 & 0,17712947 \\
\hline & & 4 & 3,905 & 5,01 & 2 & 5,77 & 0,2875929 \\
\hline \multirow{4}{*}{4.} & & 1 & 1,977 & 3,42 & 2 & 13,58 & 0,24136182 \\
\hline & 4000 & 2 & 3,091 & 5,5 & 2 & 14,3 & 0,14660202 \\
\hline & & 3 & 3,031 & 5,37 & 2 & 11,79 & 0,18133234 \\
\hline & & 4 & 2,708 & 4,79 & 2 & 10,32 & 0,23187111 \\
\hline \multirow[t]{4}{*}{5.} & & 1 & 1,124 & 2,12 & 3 & 25,09 & 0,34466667 \\
\hline & 3000 & 2 & 1,507 & 1,33 & 2 & 15,95 & 0,26958832 \\
\hline & & 3 & 2,296 & 4,89 & 2 & 14,05 & 0,20087542 \\
\hline & & 4 & 1,756 & 2,87 & 2 & 13,86 & 0,26624856 \\
\hline
\end{tabular}




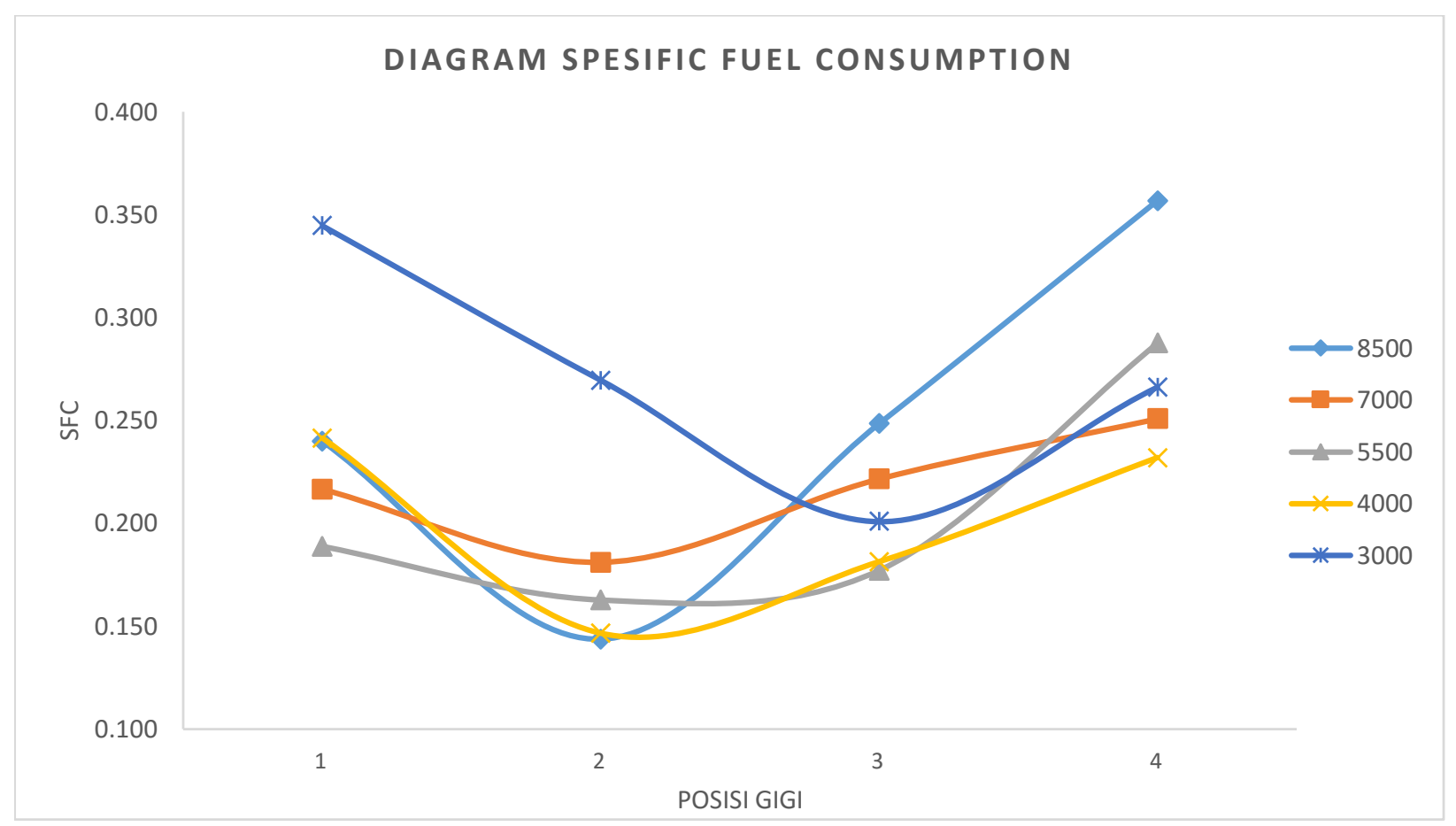

Gambar 8. Diagram SFC

\section{KESIMPULAN}

Motor upgrading ini adalah solusi dari penerapan batas ambang emisi gas buang yang melarang Motor 2 stroke beroperasi. Hasil uji performa mesin motor upgrading ini mampu mencapai putaran 8500 RPM dengan power sebesar 6, 23 HP. Hasil uji emisi menunjukkan kadar $\mathrm{CO}, \mathrm{CO}_{2}$ yang lebih rendah baik dari motor 2 stroke maupun motor 4 stroke.

\section{DAFTAR PUSTAKA}

Bisht N., Singh A., Bhargav P., Bishakha. Kabadwal T. 2012. To Study Performance of Two Stroke Engine with Modified Intake System. India.

Faiz, Asif,. Weaver S. Christopher., Walsh P. Michael. 1996. Air Pollution from Motor Vehicles. Washington DC.

Kementrian Negara Lingkungan Hidup. 2009. Peraturan Menteri Negara Lingkungan Hidup nomor 04 tahun 2009 tentang Ambang Batas Gas Buang Kendaraan Bermotor Tipe Baru. Jakarta.

Kumar, Jayath T., M. Arum, G. Murugan, R. Mano, J. Venkatesan. 2010. Modification of Two Stroke I. C Engine to Reduce Emission and Fuel Consumption. India Manufacturers of Emission Control Association.. Emission Control of Two and Three Wheel Vehicles, Washington DC.

Sanjakumar P., Ashokumar K., Tamilselvan S., Surya M. 2013. Conventional Fuel Injection System I Two Stroke Engines. India

Sipahutar, Riman. 2011. Studi Eksperimental Pengaruh Penggunaan Catalytic Converter Emisi Gas Buang Motor Yamaha Rx-King. Palembang.

Siswantoro, Lagiyono dan Siswiyanti. 2012. Analisa Emisi Gas Buang Kendaraan Bermotor 4 Tak Berbahan Bakar Campuran Premium Dengan Variasi Penambahan Zat Aditif. Tegal. 